\title{
Dermatomyositis with Kaposi's sarcoma in a patient without human immunodeficiency virus-1 infection
}

\author{
DANA LIANG, MD, ANDREW SZILAGyi, MD, FRCPC, FACP, ROBIN C BILliCK, MD, FRCPC, \\ HERBERT SROLOVITZ, MD, FRCPC, RICARDO BULLEN, MD
}

D Liang, A SzilagYi, RC Billick, H SROlovitz, R BUllen. Dermatomyositis with Kaposi's sarcoma in a patient without human immunodeficiency virus-1 infection. Can J Gastroenterol 1991;5(1):1-4. The first case of dermatomyositis complicating cutaneous and visceral Kaposi's sarcoma is presented in a 75-year-old man without human immunodeficiency virus infection. Dermatomyositis preceded a definitive diagnosis of Kaposi's sarcoma by six months, although in retrospect unrecognized lesions may have presented simultaneously. He was treated with prednisone and azathioprine, thus raising the possibility of the role of immunosuppression in promoting progression of the sarcoma. It is suggested that although the association between dermatomyositis and Kaposi's sarcoma occurs rarely, dermatomyositis should be considered a paraneoplastic syndrome of Kaposi's sarcoma. Further, the finding of cutaneous lesions of Kaposi's sarcoma could predict gastrointestinal involvement when dermatomyositis and Kaposi's sarcoma occur in the same patient

Key Words: Dermatomyositis, Kaposi's sarcoma

Dermatomyosite associée à un sarcome de Kaposi chez un patient non infecté par le virus d'immunodéficience humaine 1

RESUME: On présente un cas de dermatomyosite compliquant un sarcome de Kaposi (SK) cutané et viscéral chez un homme de 75 ans qui n'était pas infecté par le VIH. La dermatomyosite a précédé le diagnostic formel du SK de six mois, bien qu'en rétrospective des lésions méconnues aient pu se manifester simultanément. Le patient a été traité par la prednisone et l'azathioprine, ce qui évoque la possibilité du rôle de l'immunosuppression comme agent favorisant l'évolution du sarcome. On suggère que, bien que l'association dermatomyosite et sarcome de Kaposi soit rare, la dermatomyosite soit considérée comme syndrome paranéoplasique d'un sarcome de Kaposi. Plus encore, la découverte des lésions cutanées du SK pourrait évoquer une atteinte gastrointestinale quand la dermatomyosite et le sarcome de Kaposi se déclarent chez un même patient.

Department of Medicine, Division of Gastroenterology, and Departments of Dermatology and Pathology, Sir Mortimer B Davis Jewish General Hospital, McGill University, Montreal, Quebec

Correspondence and reprints: Dr A Szilagyi, 6000, Cote des Neiges, Suite 100, Montreal, Quebec H3S 128

Received for publication October 30, 1990. Accepted December 5, 1990
$\mathrm{K}$ APOSI'S SARCOMA IS A MULTI. focal neoplasm thought to be endothelial in origin (1). In recent years, Kaposi's sarcoma has emerged as a common malignancy associated with the acquired immune deficiency syndrome (AIDS) and is found in up to $30 \%$ of adult cases (2). In addition, there has been a number of reports of Kaposi's sarcoma associated with immunosuppression, usually secondary to renal transplantation (3-6), but also to the use of immunosuppressive drugs in other diseases (7-9). Dermatomyositis, although associated with other neoplasms, has been rarely described in Kaposi's sarcoma. While these latter cases describe cutaneous involvement, disseminated Kaposi's sarcoma has not been reported.

\section{CASE PRESENTATION}

A 75-year-old Sephardic Jewish man presented to the authors' institution in January 1989 with a red, scaly rash on his knuckles, scalp, face, upper chest and groin. He subsequently developed a low grade fever to $38^{\circ} \mathrm{C}$, began having difficulty with arising from a chair or bed, and noticed increasing leg fatigue with walking or climbing stairs. He was also unable to brush his teeth or comb his hair. An electromyogram of his right shoulder was suggestive of a rapidly destructive myositis, and he was ad- 
mitted to hospital for further investigation. Past medical history included asthma, myocardial infarction, hyperuricemia and an acoustic neuroma. There was no past history of blood transfusion, drug abuse, or homosexual or bisexual behaviour.

Creatine phosphokinase was 2009 $\mathrm{iu} / \mathrm{L}$ and aldolase $18 \mathrm{iu} / \mathrm{L}$. A left deltoid muscle biopsy showed an inflammatory myopathy consistent with adult dermatomyositis. He was started on oral prednisone $60 \mathrm{mg}$ daily, with improvement in his muscle weakness and lowering of creatine phosphokinase levels to the normal range. He underwent a computed tomography scan of his abdomen, barium enema and flexible sigmoidoscopy, which did not reveal evidence of underlying malignancy. A gastroduodenoscopy showed a small lesion on the greater curvature of the stomach, and a biopsy of this was reported as acute and chronic gastritis.

The patient was discharged from hospital with gradual tapering of prednisone. Azathioprine $50 \mathrm{mg}$ orally daily was subsequently added, continued for a total of six weeks, and discontinued accidentally by the patient. A red, blanchable lesion was noted on the patient's left ear by the dermatologist prior to starting the azathioprine, but was assumed to be a giant spider hemangioma.

In June 1989, the patient was re-admitted to hospital with retrosternal chest pain and a two week history of black stools. Skin examination revealed multiple new dusky violaceous macules and plaques on the chest, left ear, upper back and neck (Figure 1). A biopsy of one of these lesions was consistent with Kaposi's sarcoma (Figure 2). The hemoglobin was $85 \mathrm{~g} / \mathrm{L}$, white blood cell count $9.9 \times 10^{9} / \mathrm{L}$, platelet count $246 \times 10^{9} /$ L. Prothrombin time was $10.8 \mathrm{~s}$ and partial thromboplastin time $24.1 \mathrm{~s}$. Creatine phosphokinase was $46 \mathrm{iu} / \mathrm{L}$, aldolase $3.8 \mathrm{iu} / \mathrm{L}$, and aspartate aminotransferase $15 \mathrm{iu} / \mathrm{L}$. The patient underwent a gastroduodenoscopy which revealed multiple violaceous lesions throughout the fundus and antrum (Figure 3). A benign antral ulcer near the incisura was also found and was presumed the site of blood loss. Bleed- ing gradually stopped. A short colonoscopy to $60 \mathrm{~cm}$, barium enema and small bowel barium studies failed to reveal any lesions. A human immunodeficiency virus antibody test (enzymelinked immunosorbent assay [ELISA] method) was negative.

The patient was started on intravenous vinblastine $0.1 \mathrm{mg} / \mathrm{kg}$ week and completed two courses in hospital before discharge and a further three as an outpatient. Repeat gastroscopy, however, still showed diffuse progressive gastric Kaposi's sarcoma. Vinblastine was stopped but prednisone $20 \mathrm{mg}$ daily was continued.

In February 1990 the patient was re-admitted for increasing frequency of retrosternal chest pain, increasing dyspnea on exertion and progressive proximal muscle weakness over a one month period. He denied symptoms of hematemesis, melena or bright red blood per rectum. New skin lesions had appeared in the preceding months prior to admission.

Physical examination at this time revealed an alert, pale man in no acute distress. The blood pressure was 110/49 $\mathrm{mmHg}$, pulse rate was 90 beats/min with no postural drop. General examination revealed multiple violaceous oval and round macules and plaques on the hard palate, the trunk, upper extremities, inguinal area and thighs. Cardiovascular examination was within normal limits. Abdominal examination revealed no evidence of organomegaly. Rectal examination revealed brown stool negative on guaiac testing. Extremity examination revealed pitting edema bilaterally below the knee, and proximal muscle weakness of both lower extremities. The hemoglobin was $77 \mathrm{~g} / \mathrm{L}$, white blood cell count $14.4 \times 10^{9} / \mathrm{L}$, and platelet count $283 \times 10^{9} /$ L. Prothrombin time was $12 \mathrm{~s}$, and partial thromboplastin time was 28.7 s. Reticulocyte count was $30 \times 10^{-3}$ $\mathrm{g} / \mathrm{L}$, Coomb's direct test was negative, and haptoglobin was $1.51 \mathrm{~g} / \mathrm{L}$. Creatine phosphokinase was $1737 \mathrm{iu} / \mathrm{L}$, aldolase $16 \mathrm{iu} / \mathrm{L}$, and aspartate aminotransferase $145 \mathrm{iu} / \mathrm{L}$. Creatinine was $143 \mathrm{mmol} / \mathrm{L}$ and urea $15.2 \mathrm{mmol} / \mathrm{L}$. A repeat human immunodeficiency virus-1 test (ELISA) was negative.

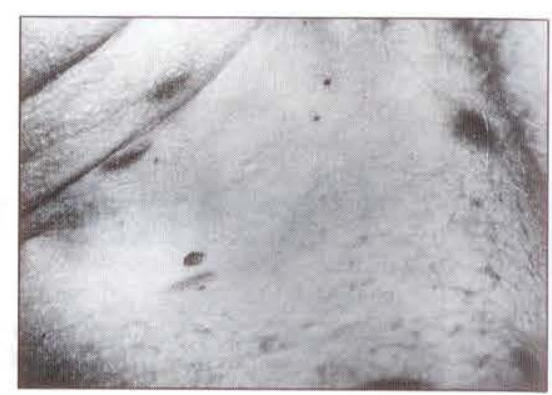

Figure 1) Four elliptical round maculopapular erythematous lesions of Kaposi's sarcoma, two of which follow skin folds on the left side of the neck

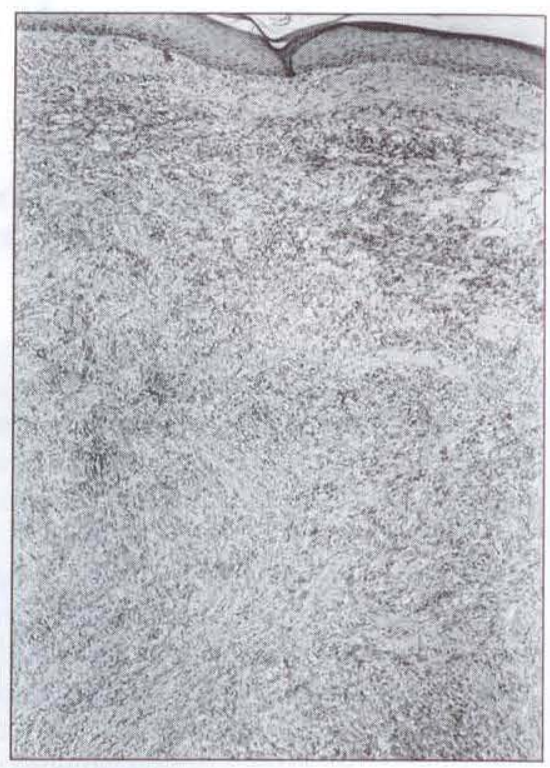

Figure 2) Attenuated epidermis from a fasciculated spindle cell tumour with mononuclear inflammatory cells in the dermis (hematoxylin and eosin stain $\times 50$ )

Prednisone was increased to a daily oral dose of $60 \mathrm{mg}$. Gastroduodenoscopy showed multiple lesions, more numerous than on previous inspections, in the body and antrum of the stomach and in the first and second stages of the duodenum (Figure 3). No lesions were actively bleeding. The patient was restarted on vinblastine therapy at a dose of $7 \mathrm{mg}$ weekly. Four days after the first infusion of vinblastine, the hemoglobin decreased to $77 \mathrm{~g} / \mathrm{L}$ and white blood cell count to $2.9 \times 10^{9} / \mathrm{L}$. Guaiac testing of stool became positive. Bone marrow examination revealed decreased iron stores and changes consistent with drug-induced marrow dysplasia, but was negative for Kaposi's sarcoma. The patient was noted to have marked 

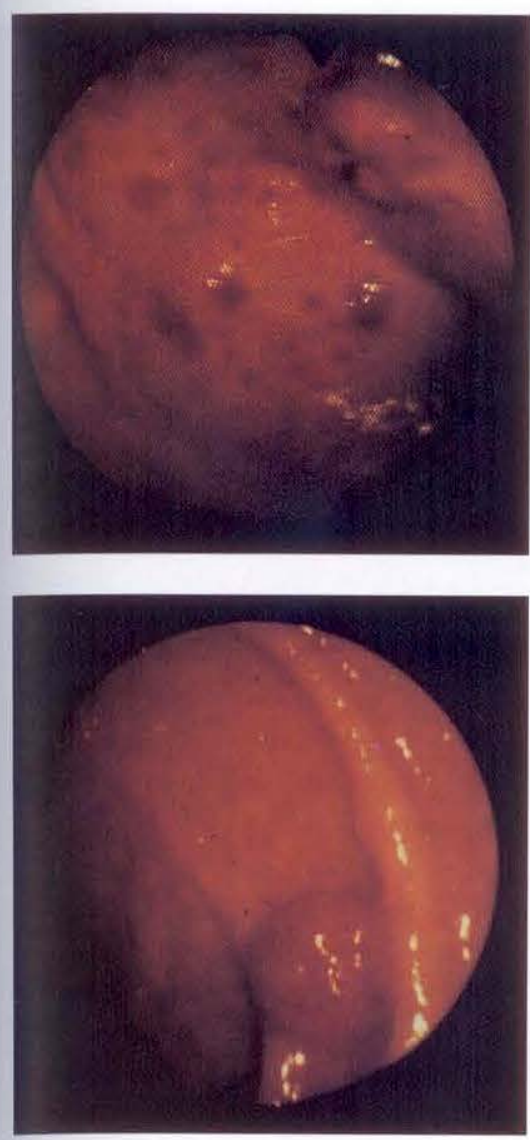

Figure 3) Top Endoscopic view of fundus and antrum showing multiple raised nodules ranging in size from 2 to $6 \mathrm{~mm}$ in diameter. An ulcer at the incisura is seen near the arrow. Bottom A 6 mm nodule is seen in the second portion of the duodenum

wheezing on respiratory examination. Two days later, the patient became hypotensive. A nasogastric tube was inserted which showed no evidence of upper gastrointestinal hemorrhage. The patient subsequently expired and a post mortem examination was refused. Restaining of the gastric biopsy obtained in January 1989 was positive for factor VIII (10) (Figure 4), suggesting that the original nodule could have been an early manifestation of Kaposi's sarcoma involving the stomach.

\section{DISCUSSION}

Kaposi's sarcoma is by far the most common neoplasm found in AIDS patients, and is a multifocal vascular tumour which involves skin, mucous membranes, lymph nodes and visceral organs. In homosexual patients, the disease tends to be aggressive, with fre-

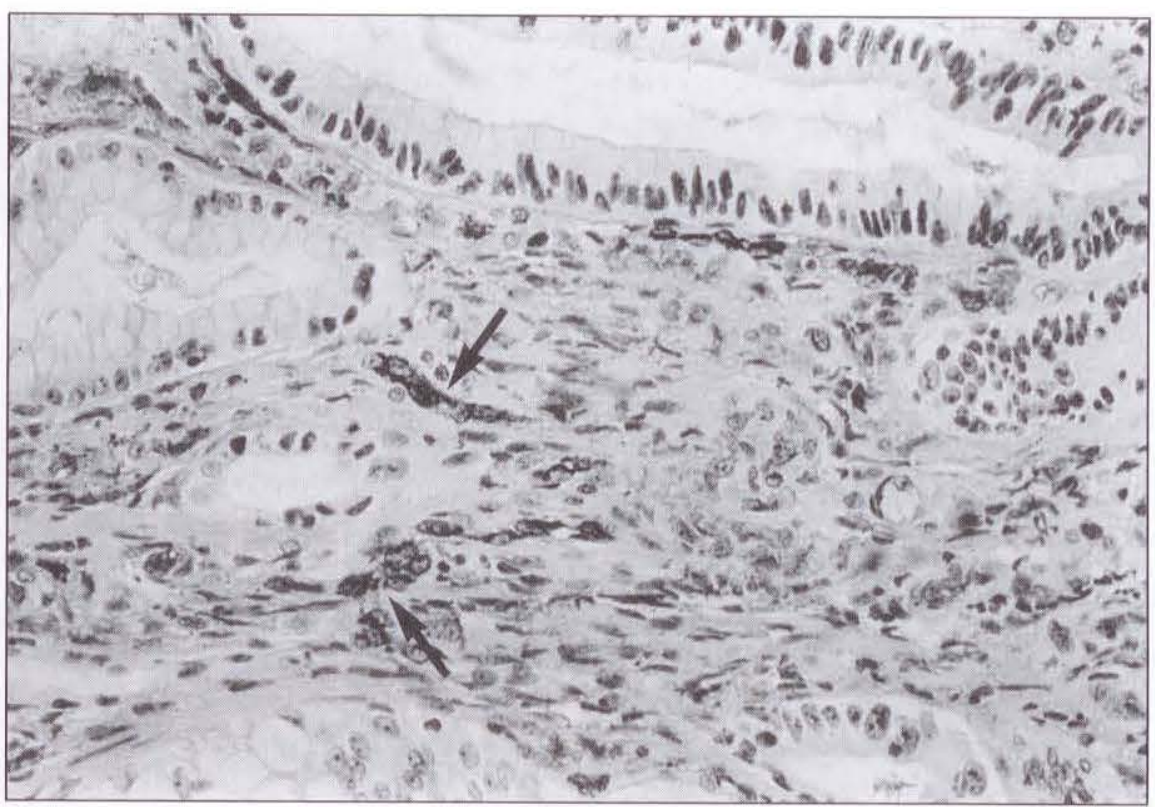

Figure 4) Gastric mucosa showing spindle cells within lamina propria reactive to factor VIII with peroxidase immunoperoxidase staining (arrows) (x175)

quent involvement of multiple mucosal surfaces, visceral organs, lymph nodes and skin. Specifically, gastrointestinal involvement occurs in up to $50 \%$ of patients, usually without symptoms. Complications that can occur are gastrointestinal hemorrhage, perforation and severe diarrhea (2).

The classic form of Kaposi's sarcoma in the United States and Europe is a rare tumour usually found in elderly men. Most of these cases occur in men of Mediterranean or Jewish origin, with a lower incidence of visceral dissemination $(10 \%)$. The present patient probably belonged to this latter group because of the lack of human immunodeficiency virus-1 risk factors and two negative tests for human immunodeficiency virus- 1 separated by at least six months.

Kaposi's sarcoma is also seen in association with immunosuppressive drugs such as azathioprine and corticosteroids. Other agents which have been implicated include cyclophosphamide, melphalan and radiation therapy $(11,12)$. Numerous cases have been reported in the literature, mostly associated with renal transplantation but also with rheumatoid arthritis, lymphoma, myeloma, asthma, systemic lupus erythematosus, pemphigus vulgaris, bullous pemphigoid, biliary cir- rhosis, nephrotic syndrome, hemolytic anemia, immune thrombocytopenic purpura, polymyositis and dermatomyositis $(11,12)$. Most cases of Kaposi's sarcoma appearing in the literature associated with immunosuppression are limited to cutaneous involvement; however, there are several cases of diffuse visceral involvement in the setting of renal transplantation and multiple immunosuppressive drugs $(4,6)$.

It is interesting that in renal transplant patients who developed Kaposi's sarcoma, Mediterranean or Jewish origin could be traced in all (6). In contrast, in a large series of transplant recipients (primarily Anglo-Saxon) in Australia and New Zealand, no cases of Kaposi's sarcoma were seen (13).

Harwood et al (6) postulated that the etiology of Kaposi's sarcoma was multifactorial, and that the combination of a hereditary predisposition and immunological factors resulted in a major increase in the risk of developing the disease. To date, the exact mechanism of development of Kaposi's sarcoma in this setting is unknown; however, patients with abnormalities of immune function have a higher than expected incidence of malignancy. Three major mechanisms that have been postulated include: chronic antigenic stimulation by grafted tissue in 
transplant patients; loss of surveillance mechanisms against proliferating malignant cells resulting from depression of immune responsiveness by immunosuppressive agents; and virusinduced oncogenesis (3).

Kaposi's sarcoma coinciding with dermatomyositis or polymyositis, a disease known to be associated with various internal malignancies, has been reported in only three other patients $(7,14,15)$. In each of these cases Kaposi's sarcoma was noted to be limited to the skin. In the present case, lesions were noted on the skin and in the stomach, which then subsequently progressed to involve the small bowel and perhaps the lung, although this was never proven. The relationship of dermatomyositis to Kaposi's sarcoma is unclear. Although the most common tumours related to dermatomyositis usually originate in the stomach, lung, prostate, breasts, gall bladder and female genitalia (16), Kaposi's sarcoma has not been previously reported without concomitant immunosuppression. However, the authors feel that the ini-

\section{REFERENCES}

1. Flotte TJ, Hatcher VA, Friedman-Kien AE. Factor VIII-related antigen in Kaposi's sarcoma in young homosexual men. Arch Dermatol 1984;120:180-2.

2. Steis RG, Longo DL. Clinical, biologic, and therapeutic aspects of malignancies associated with the acquired immunodeficiency syndrome. Ann Allergy 1988;60:310-21.

3. Myers BD, Kessler E, Levi J, Pick A, Rosenfeld JB, Tivkah P. Kaposi sarcoma in kidney transplant recipients. Arch Intern Med 1974;133:307-11.

4. Siegel JH, Janis R, Alper JC, Schutte H, Robbins L, Blaufox D. Disseminated visceral Kaposi's sarcoma. JAMA 1969;207:1493-6.

5. Penn I, Starzl TE. Malignant tumors arising de novo in immunosuppressed organ transplant recipients.

Transplantation 1972;14:407-17.

6. Harwood AR, Osoba D, Hofstader SL, tial red macule noted on the patient's left ear five months prior to the definitive diagnosis of Kaposi's sarcoma, as well as the nodule noted on first gastroscopy, may have been the first signs of Kaposi's sarcoma. Positive immunoperoxidase stains for factor VIII antigen support the presence of active endothelial cell proliferation (10). Such a coincidental synchronous occurrence of Kaposi's sarcoma has been reported in a single case of polymyositis (14). However, the lack of definite, biopsyproven skin lesions at the earlier time, and the known association of Kaposi's sarcoma with immunosuppression, leads one to consider that the aggressive nature of Kaposi's sarcoma in the present patient may have been promoted by therapy with prednisone and azathioprine. The stable clinical course of dermatomyositis at the time of diagnosis of Kaposi's sarcoma also lends support to this notion.

Regression of Kaposi's sarcoma after discontinuation of immunosuppressive treatment is a hallmark (16). However, the present patient was unable to have

et al. Kaposi's sarcoma in recipients of renal transplants. Am J Med 1979;67:759-65.

7. Weiss VC, Serushan M. Kaposi's sarcoma in a patient with dermatomyositis receiving immunosuppressive therapy. Arch Dermatol 1982;118:183-5.

8. Hoshaw RA, Schwartz RA. Kaposi's sarcoma after immunosuppressive therapy with prednisone. Arch Dermatol 1980;116:1280-2.

9. Klein MB, Pereira FA, Kantor I. Kaposi sarcoma complicating systemic lupus erythematosus treated with immunosuppression. Arch Dermatol 1974; 110:602-4.

10. Nadji M, Morales AR. Immunoperoxidase techniques. A practical approach to tumor diagnosis. Chicago: American Society of Clinical Pathologists Press, 1986:18-21.

11. Gagne RW, Wilson-Jones E. Kaposi's sarcoma and immunosuppressive prednisone decreased beyond $20 \mathrm{mg}$ orally every other day because of reactivation of the dermatomyositis.

Therapy of visceral Kaposi's sarcoma is associated w:th a poor response. Interferon, vinblastine chemotherapy, and combination chemotherapy have been used in AIDS patients with good results in the least immunosuppressed patients and early stage disease. (2) In non-AIDS patients with Kaposi's sarcoma, there is little information on therapy with interferon (17).

In conclusion, a case of dermatomyositis associated with visceral Kaposi's sarcoma, possibly exacerbated by immunosuppression, has been reported. This is to the authors' knowledge the first report of an association of dermatomyositis with visceral Kaposi's sarcoma. Therefore, dermatomyositis may be considered a paraneoplastic syndrome of Kaposi's sarcoma. Furthermore, the presence of cutaneous Kaposi's sarcoma lesions when dermatomyositis and Kaposi's sarcoma occur together suggests that gastrointestinal involvement may also be present.

therapy: An appraisal. Clin Exp Dermatol 1978;3:135-46.

12. Klepp O, Dahl O, Stenwig JT. Association of Kaposi's sarcoma and prior immunosuppressive therapy. Cancer 1978;42:2626-30.

13. Sheil AGR. Cancer in renal allograft recipients in Australia and New Zealand. Transplant Proc 1977;9:1133.

14. Dantzig PI. Kaposi sarcoma and polymyositis. Arch Dermatol 1974;110:605-7.

15. Weiner SR, Noritake DT, Paulus ME. Kaposi's sarcoma in a patient with rheumatoid arthritis and polymyositis treated with corticosteroids. West J Med 1988;148:702-3.

16. Talbott JH. Acute dermatomyositispolymyositis and malignancy. Semin Arthritis Rheum 1977;6:305-58.

17. Botev N, Berova N, Andreev V. Our experience of the treatment of selected dermatoses with interferon alpha 2A. J Invest Dermatol 1989;93:543. 


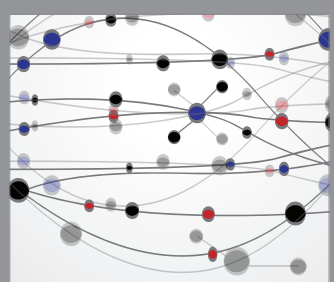

The Scientific World Journal
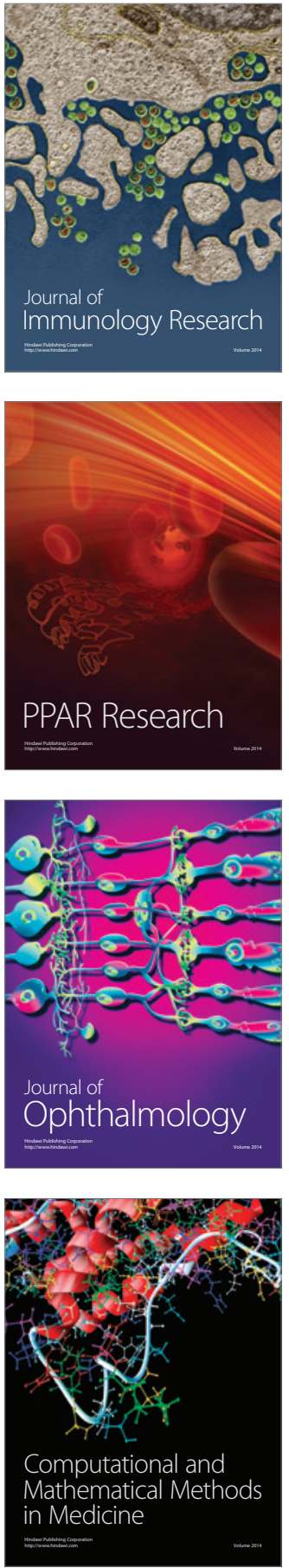

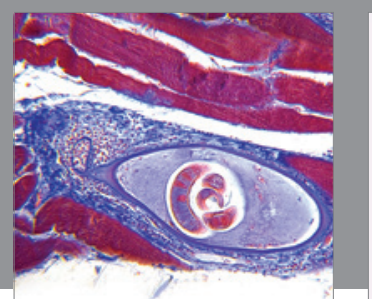

Gastroenterology Research and Practice

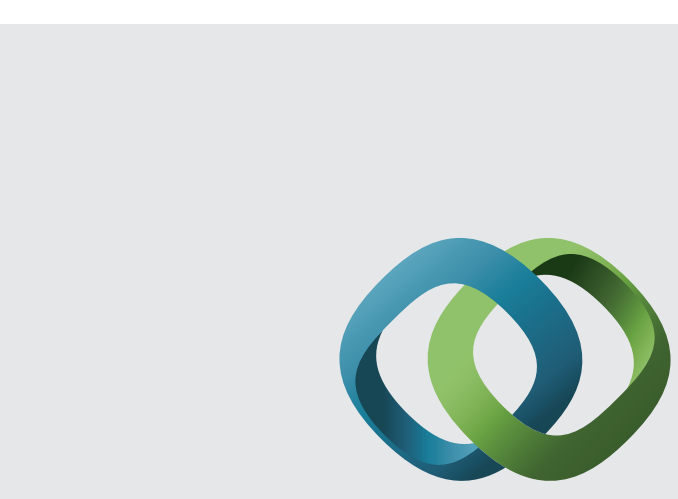

\section{Hindawi}

Submit your manuscripts at

http://www.hindawi.com
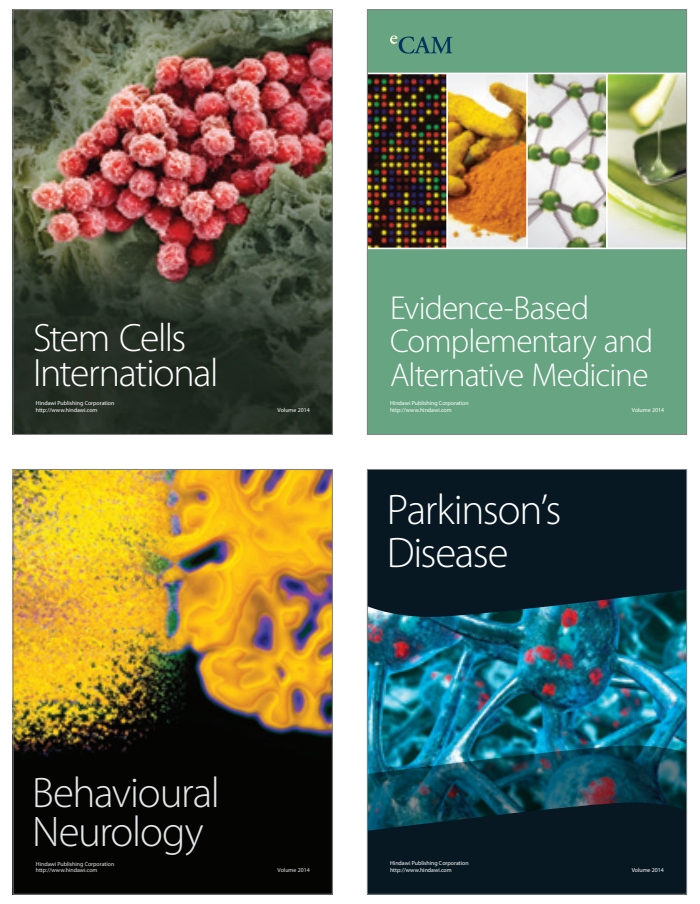
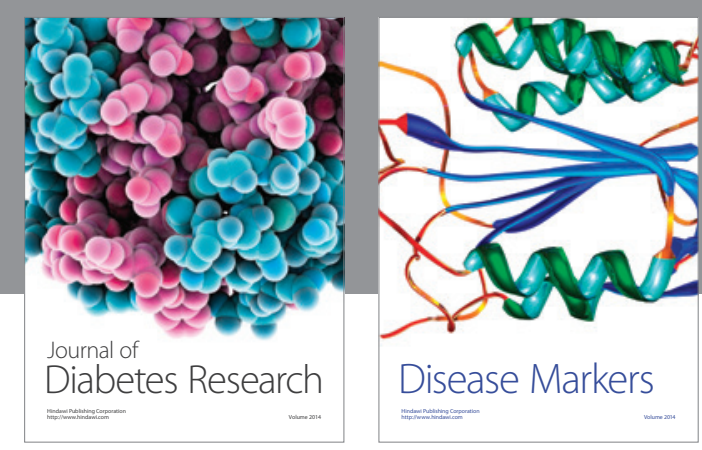

Disease Markers
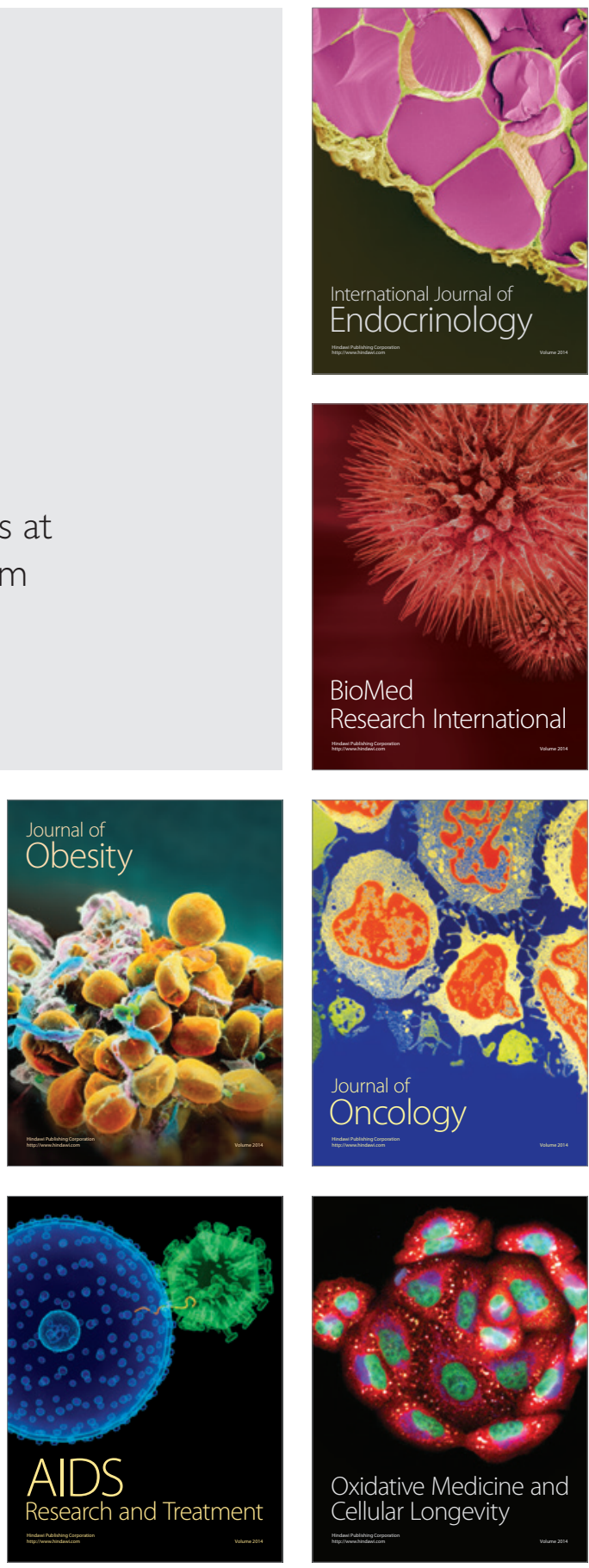